\title{
A Prospective Cohort Study of Maternal and Perinatal Outcome in Pregnancy with First-trimester Vaginal Bleeding
}

\author{
${ }^{1}$ Shaheen Hokabaj, ${ }^{2}$ Mallikarjun Rashmi, ${ }^{3}$ Priyankur Roy, ${ }^{4}$ Suguna Shanthi, ${ }^{5}$ Chitra Karat, ${ }^{6}$ Ruchika Garg
}

\begin{abstract}
Aims and objectives: The objectives are to study the effect of vaginal bleeding during first trimester of an intrauterine pregnancy on maternal and perinatal outcomes.

Materials and methods: A prospective cohort study was conducted over a duration of 2 years of 430 pregnant women. Data of 210 and 176 women in the study and control group were studied respectively. Study group comprised of women with first-trimester vaginal bleeding and control group comprised of women with no vaginal bleeding, after ultrasonography (USG) confirmation of intrauterine pregnancy done routinely in all women. Maternal and perinatal outcomes were studied in both groups.
\end{abstract}

Results: The two groups were matched in terms of age, parity, socioeconomic status, and body mass index (BMI), and no statistically significant difference was detected in these parameters. A total of 104 women (49.5\%) had bleeding during 7 to 8 weeks of gestation. Miscarriage occurred in 96 women (45.7\%) with first-trimester vaginal bleeding in study group compared with 20 women (10.2\%) among control group; $54.3 \%$ women in the study group and $89.8 \%$ of women in control group had continuation of pregnancy. The most common type of miscarriage was missed miscarriage $(40 ; 19 \%)$ in the study group. Maternal complications occurred more in the study group $(74 ; 64.9 \%)$ as compared with 28 (15.9\%) in the control group during the course of pregnancy. The incidence of preterm deliveries was higher in the study group (17.5\%) than in the control group (2.3\%). Most of the women in both the groups delivered by vaginal route. Overall, neonatal complications were higher in the study group $(49.1 \%)$. The mean birth weight was significantly lower in the study group as compared with control group.

\footnotetext{
${ }^{1}$ Clinical Fellow, ${ }^{2,5}$ Consultant, ${ }^{3}$ Tutor, ${ }^{4}$ Senior Consultant ${ }^{6}$ Associate Professor

${ }^{1}$ Department of Obstetrics and Gynecology, Smt. G.R. Doshi and Smt. K.M. Mehta Institute of Kidney Diseases and Research Centre, Ahmedabad, Gujarat, India

2,4,5Department of Obstetrics and Gynecology, CSI Holdsworth Memorial (Mission) Hospital, Mysuru, Karnataka, India

${ }^{3}$ Department of Obstetrics and Gynecology, North Bengal Medical College \& Hospital, Siliguri, West Bengal, India

${ }^{6}$ Department of Obstetrics and Gynecology, Sarojini Naidu Medical College, Agra, Uttar Pradesh, India

Corresponding Author: Shaheen Hokabaj, Clinical Fellow Department of Obstetrics and Gynecology, Smt. G.R. Doshi and Smt. K.M. Mehta Institute of Kidney Diseases and Research Centre, Ahmedabad, Gujarat, India, e-mail: shaheenhokabaj@ gmail.com
}

Conclusion: Women with first-trimester vaginal bleeding are at increased risk of adverse pregnancy outcomes, such as spontaneous miscarriage, preterm premature rupture of membranes (PPROM), premature rupture of membranes (PROM), intrauterine growth retardation (IUGR), oligohydramnios, low birth weight (LBW), preterm delivery, and increased perinatal morbidity.

Keywords: First trimester, Maternal outcome, Miscarriage, Perinatal outcome, Vaginal bleeding.

How to cite this article: Hokabaj S, Rashmi M, Roy P, Shanthi S, Karat C, Garg R. A Prospective Cohort Study of Maternal and Perinatal Outcome in Pregnancy with First-trimester Vaginal Bleeding. J South Asian Feder Obst Gynae 2018;10(1):49-53.

Source of support: Nil

Conflict of interest: None

Date of received: 15 January 2018

Date of acceptance: 25 February 2018

Date of publication: May 2018

\section{INTRODUCTION}

Vaginal bleeding is a common and alarming symptom during early pregnancy, which can evoke feelings of shock, disorganization, and guilt. Prevalence of firsttrimester vaginal bleeding ranges from 7 to $24 \%$ of all pregnancies. First-trimester bleeding is considered as a marker of a general proclivity to other pregnancy complications surfacing later in the pregnancy. Cause of vaginal bleeding remains unknown in about $50 \%$ of cases and most often originates because of defective placentation.

Fetal loss is a risk factor for mental illness. ${ }^{1}$ Women who had undergone an abortion experienced $81 \%$ increased risk of mental health problems. Its impact on a woman's life can erroneously be underestimated. ${ }^{2}$ Incidence of spontaneous abortion after first-trimester bleeding is around $50 \%$ before ultrasonographic evidence of fetal viability, and it diminishes from 2 to $14 \%$ after confirmation of viability. ${ }^{3}$

Bleeding between the chorionic membrane and the uterine wall can result in a spectrum of effects ${ }^{4}$ :

- Direct pressure and disruption of placental bed result in miscarriage

- Chronic inflammatory reaction within the decidua and placental membranes results in weakening and eventually rupture of the membranes or onset of myometrial activity. 
Complications like placental abruption, PPROM, preterm delivery, preeclampsia, IUGR, and fetal death can occur. Therefore, knowledge about the outcome of ongoing pregnancies following first-trimester bleeding is of relevance to women and obstetricians for planning antenatal care and also to identify need for early clinical interventions in pregnancy, if required.

In order to understand other risks of first-trimester bleeding, we evaluated the incidence of a variety of placental and nonplacental outcomes, such as pregnancy loss, preterm delivery, IUGR, preeclampsia, PPROM, placental abruption, placenta previa, and cesarean delivery in pregnancies with first-trimester bleeding.

\section{MATERIALS AND METHODS}

A total of 430 women reporting to the Department of Obstetrics and Gynaecology, CSI Holdsworth Memorial Hospital, Mysuru, during the first trimester of pregnancy were recruited for the study. All 430 patients underwent USG for confirmation of an intrauterine pregnancy.

\section{Study Outcome}

To study the effects of vaginal bleeding during first trimester on maternal and perinatal outcomes.

\section{Study Design}

Cohort study.

\section{Sample Size Calculation}

$$
S=\frac{Z^{2} p q}{d^{2}}=\frac{1.96 \times 1.96 \times 0.15 \times 0.85}{0.05 \times 0.05}=195.9
$$

S-Sample size

Z-Z value (1.96 for $95 \%$ confidence level)

$\mathrm{p}$-Prevalence

$\mathrm{q}-1-\mathrm{p}$

$\mathrm{d}-0.05$ (margin of error)

The minimum required sample size for a significant result was 200. Thus, the sample size for the study group (215) was calculated to reach a significant result and the number was matched in the control group as well. In the 2 years when the study was conducted, a total of 430 women were recruited for the study.

\section{Study Duration}

Two years.

\section{Informed Consent}

After explaining and obtaining written informed consent from all the women and attenders, they were recruited in the study.

\section{Inclusion Criteria}

- Study subject: Women presenting with vaginal bleeding and USG confirmed intrauterine pregnancy during first trimester (less than 14 completed weeks of gestation) regardless of pregnancy viability were included in study group

- Control subject: Pregnant women with no history of vaginal bleeding during first trimester of USG confirmed intrauterine pregnancy.

\section{Exclusion Criteria}

- Hydatidiform mole

- Multiple pregnancy

- Congenital uterine anomalies

- Pelvic benign and malignant tumors distorting the uterine cavity

- Local cervical and vaginal lesions causing bleeding

- Bleeding disorders.

A comprehensive assessment was done emphasizing on various aspects of history (obstetric, menstrual, personal, past and family history), and previous pregnancy details including history of miscarriage, preterm delivery, previous mode of delivery. Gestational age was calculated using last menstrual period. If this was unavailable, ultrasound-based gestational age was used. Detailed history of bleeding including amount, duration, and associated abdominal pain was recorded. Socioeconomic status was categorized according to modified Kuppuswamy classification. ${ }^{5}$ Age, parity, socioeconomic status, and BMI-matched pregnant women after ultrasonographic confirmation of intrauterine pregnancy were included in the study.

A detailed clinical examination including assessment for pallor, edema, and systemic examination; speculum examination for assessment of bleeding characteristics and cervical change; bimanual pelvic examination for assessment of uterine size, cervical changes, and to identify any evidence of miscarriage was done.

Patients were investigated with necessary laboratory investigations including urinalysis, biochemical, hematological, and serological tests. All patients were evaluated using transabdominal or transvaginal USG. The USG parameters included:

- Estimation of gestational age

- Differentiation of viable vs nonviable pregnancy

- Type of miscarriage.

All those women who continued pregnancy were followed up prospectively from their first appointment till delivery. The follow-up was done every 4 weeks till 28 weeks of gestation, every 2 weeks from 29 to 34 weeks, and thereafter every weekly till delivery. The USG was done at least three times during pregnancy, one each at 11 to 13,18 to 20 , and 32 to 34 weeks in all women. 
A pro forma was formulated to record personal details of women, clinical examination findings, ultrasound findings, investigations, and maternal and fetal outcomes.

\section{RESULTS}

A total of 430 antenatal women, who were booked at our tertiary care hospital, were included in the study. Out of the 215 women in each group, 5 women were lost to follow-up in the study group, whereas in the control group, 19 women were lost to follow-up. In the control group, another 20 women underwent miscarriage and were excluded from the study. Hence, data of 210 women and 176 women in the study and control group were studied respectively.

The mean maternal age for the study and control group was 25.2 and 24.4 years respectively. The most common age group at presentation in our study was 21 to 25 years (Graph 1). Majority of women in both groups belonged to upper middle and lower middle class according to modified Kuppuswamy classification (Table 1). Majority of women were multigravida in both the groups (Table 2). Both study and control groups were matched in terms of BMI.

In our study, majority of women, i.e., 104 (49.5\%), presented between 7 and 8 weeks of gestation with vaginal bleeding (Table 3). The difference in gestational age of presentation in women with bleeding per vaginum was

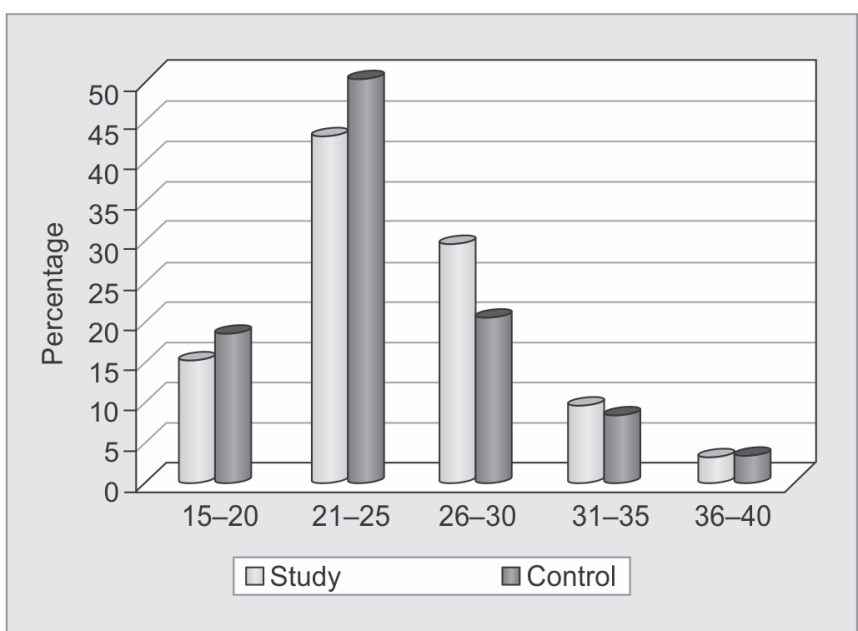

Graph 1: Age distribution

Table 1: Socioeconomic status

\begin{tabular}{lllllll}
\hline \multirow{2}{*}{$\begin{array}{l}\text { Socioeconomic } \\
\text { status }\end{array}$} & \multicolumn{2}{c}{ Study } & & \multicolumn{2}{c}{ Control } & \\
\cline { 2 - 3 } & No & $\%$ & & No & $\%$ & Total \\
\hline Upper & 16 & 7.6 & & 8 & 4.6 & 24 \\
Upper middle & 48 & 22.9 & & 56 & 31.8 & 104 \\
Lower middle & 118 & 56.2 & & 92 & 52.3 & 210 \\
Upper lower & 24 & 11.4 & & 18 & 10.2 & 42 \\
Lower & 4 & 1.9 & & 2 & 1.1 & 6 \\
\hline Total & 210 & 100 & & 176 & 100 & 386 \\
\hline
\end{tabular}

statistically significant $(\mathrm{p}<0.001)$. A total of 96 women $(45.7 \%)$ had miscarriage among study group compared with 20 women $(10.2 \%)$ among control group. In this study, 114 women (54.3\%) in study group and 176 women $(89.8 \%)$ in control group had continuation of pregnancy. The difference was statistically significant $(\mathrm{p}<0.001$; Table 4).

The most common type of miscarriage among study group was missed miscarriage in 40 women (19\%) followed by incomplete miscarriage in $22(10.5 \%)$, while in control group the most common was incomplete miscarriage in 8 women $(4.1 \%)$. The difference between the two groups was statistically significant.

Among 114 women of study group who had continuation of pregnancy, 74 women (64.9\%) had maternal complication during the course of pregnancy, whereas only 28 women $(15.9 \%)$ belonging to control group had complications. The difference was statistically significant $(p<0.001)$. There were instances where two or more complications existed in one woman. A total of 36 women (31.6\%) had PROM; PPROM was noted in 14 women (12.3\%); 20 women (17.5\%) had preeclampsia; 2 women (1.8\%) had eclampsia; IUGR in the fetus was noted in 18 women (15.8\%); oligohydramnios on USG was noted in 20 women $(17.5 \%)$; and placental abruption was seen in 6 women (5.3\%). In the

Table 2: Parity distribution

\begin{tabular}{lllllll}
\hline & \multicolumn{2}{c}{ Study } & & \multicolumn{2}{c}{ Control } & \\
\cline { 2 - 3 } Gravida & No & $\%$ & & No & $\%$ & Total \\
\hline Primigravida & 92 & 43.8 & & 74 & 42.0 & 166 \\
Multigravida & 118 & 56.2 & & 102 & 58.0 & 220 \\
\hline
\end{tabular}

Table 3: Gestational age at bleeding

\begin{tabular}{lll}
\hline $\begin{array}{l}\text { Gestational age at } \\
\text { bleeding (weeks) }\end{array}$ & No. of patients & $\%$ \\
\hline$<6$ & 8 & 3.8 \\
$7-8$ & 104 & 49.5 \\
$9-10$ & 30 & 14.3 \\
$11-12$ & 54 & 25.7 \\
$12-14$ & 14 & 6.7 \\
\hline Total & 210 & 100.0 \\
\hline$p<0.001$ & &
\end{tabular}

Table 4: Types of miscarriages

\begin{tabular}{lllllll}
\hline & \multicolumn{2}{c}{ Study } & & \multicolumn{2}{c}{ Control } & \\
\cline { 2 - 3 } & No & $\%$ & & No & $\%$ & Total \\
\hline No miscarriage & 114 & 54.3 & & 176 & 89.8 & 290 \\
Complete miscarriage & 20 & 9.5 & & 4 & 2.0 & 24 \\
Incomplete miscarriage & 22 & 10.5 & & 8 & 4.2 & 30 \\
Missed miscarriage & 40 & 19.0 & & 4 & $2.0 \%$ & 44 \\
Inevitable miscarriage & 6 & 2.9 & & 4 & 2.0 & 10 \\
Blighted ovum & 8 & 3.8 & & 0 & 0 & 8 \\
\hline Total & 210 & 100 & 196 & 100 & 406 \\
\hline$p<0.001$ & & & & &
\end{tabular}


Table 5: Mode of delivery

\begin{tabular}{llllllll}
\hline \multirow{2}{*}{ Term } & \multicolumn{2}{c}{ Study } & & \multicolumn{2}{c}{ Control } & \\
\cline { 2 - 3 }$n$ & No & $\%$ & & No & $\%$ & Total \\
\hline Full-term delivery & 94 & 82.5 & & 172 & 97.7 & 266 \\
Preterm delivery & 20 & 17.5 & & 4 & $2.3 \%$ & 24 \\
\hline Total & 114 & 100 & & 176 & 100 & 290 \\
\hline$p<0.001$ & & & & &
\end{tabular}

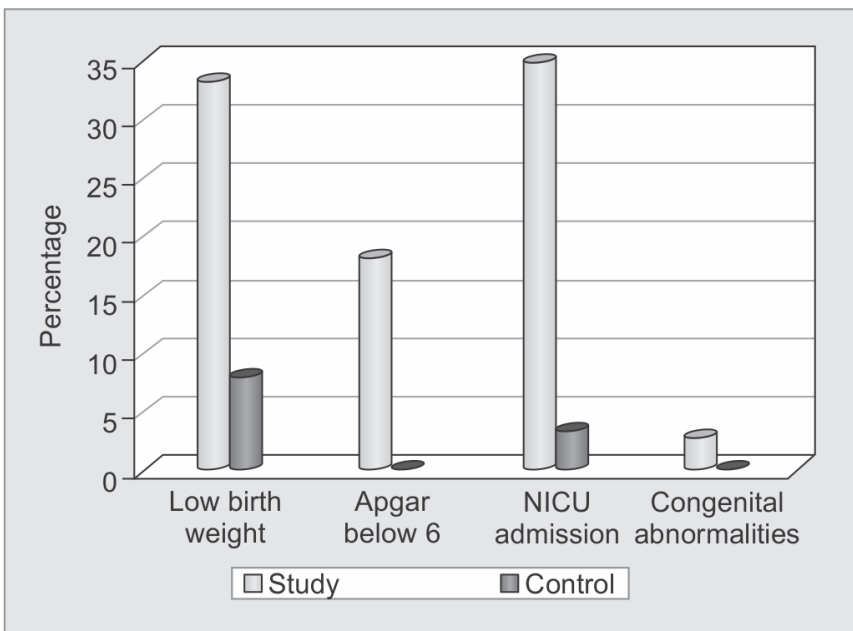

Graph 2: Neonatal complications

control group, preeclampsia was the major complication noted, accounting for approximately 16 women $(9.1 \%)$.

A total of 20 women (17.5\%) in the study group and 4 women $(2.3 \%)$ in the control group delivered preterm babies (Table 5). The difference between the two groups was statistically significant. The primary mode of delivery in both the groups was by vaginal route (194 women; $66.9 \%$ ). The mean birth weight was significantly lower in the study group $(2.63 \mathrm{~kg})$ as compared with control group $(2.98 \mathrm{~kg} ; \mathrm{p}<0.001)$.

Neonatal complications were seen in 56 babies (49.1\%) in study group as compared with 16 babies $(9.12 \%)$ in the control group. A total of 38 babies (33.3\%) of study group and 14 babies (8.0\%) of control group had LBW. Low Apgar score at 5 minutes $(\leq 6)$ was seen in 20 babies in the study group, whereas it was $\geq 7$ in all the babies in control group. There were 40 babies (35\%) admitted to neonatal intensive care unit (NICU) in the study group as compared with 6 babies (3.4\%) in the control group. There was statistical significance between the study and control groups in all the above neonatal data $(\mathrm{p}<0.001)$. Congenital abnormalities were found only in 2 babies of the study group and none of the control group (Graph 2).

\section{DISCUSSION}

First trimester vaginal bleeding is one of the most common complications of pregnancy. A total of 430 antenatal women who were booked at our tertiary care hospital were included in study. Data of 210 women and
176 women in the study and control group were studied respectively. The two groups were matched in terms of age, parity, socioeconomic status and BMI, and no statistically significant difference was detected in these parameters. The results of basic characteristic in our study was comparable to studies done by Dongol et $\mathrm{al}^{6}$ and Ahmed et al. ${ }^{7}$

In present study, majority $104(49.5 \%)$ of women with first trimester bleeding presented between 7-8 weeks of gestation, similar to the study by Hasan et al. ${ }^{3}$ The timing of this peak coincides with the shift from luteal production to placental production of progesterone and can result in a temporary reduction in progesterone level if insufficiently produced by placenta. This may trigger an episode of vaginal bleeding and limit successful maintenance of the pregnancy. Thus, bleeding at this time in pregnancy may signal that early placenta has not developed optimally.

In the current study, $45.7 \%$ women had miscarriage in study group as compared to $10.2 \%$ in control group; $54.3 \%$ women had continuation of pregnancy in the study group. This was consistent with previous studies that quoted incidence of spontaneous miscarriage after first trimester bleeding to be around $50 \%{ }^{4}$

The incidence of different types of miscarriages in present study were consistent with the study done by Boriboonhirunsarn et al (Table 6). ${ }^{8}$

The overall adverse maternal complication was significantly higher in women in the study group (64.9\%). The most common complications included PROM, preeclampsia, and IUGR. These results were similar to the observations of Ahmed et $\mathrm{al}^{7}$ and Amirkhani et al. ${ }^{9}$ Preterm deliveries were significantly higher in patients with threatened miscarriage (17.5\%), as compared with $2.3 \%$ in the control group. This observation was in coherence with Lykke et al, ${ }^{4}$ Velez Edwards et al, ${ }^{10}$ Dadkhah et $\mathrm{al}^{11}$ and Saraswat et $\mathrm{al}^{12}$ studies.

In the present study, $63.2 \%$ women had vaginal delivery, $31.6 \%$ had cesarean delivery, and $5.3 \%$ had instrumental delivery in the study group. The cesarean delivery rate was similar in the study $(31.6 \%)$ and control (29.5\%) groups. There was no statistical significance of the

Table 6: Types of miscarriages

\begin{tabular}{lll}
\hline & $\begin{array}{l}\text { Present } \\
\text { study }\end{array}$ & $\begin{array}{l}\text { Boriboonhirunsarn and } \\
\text { buranawattanachoke }\end{array}$ \\
\hline $\begin{array}{l}\text { Viable pregnancy/threatened } \\
\text { miscarriage }\end{array}$ & $54.3 \%$ & $42.3 \%$ \\
$\begin{array}{l}\text { Embryonic death/missed } \\
\text { miscarriage }\end{array}$ & $19.0 \%$ & $22.9 \%$ \\
Incomplete miscarriage & $10.5 \%$ & $3.2 \%$ \\
Complete miscarriage & $9.5 \%$ & $3.1 \%$ \\
Anembryonic pregnancy & $3.8 \%$ & $22.7 \%$ \\
Inevitable miscarriage & $2.9 \%$ & - \\
\hline
\end{tabular}


mode of delivery between the two groups. This was in accordance with the meta-analysis by Dadkhah et $\mathrm{al}^{11}$ and Saraswat et $\mathrm{al}^{12}{ }^{12}$ who found that first-trimester bleeding did not appear to influence the mode of delivery.

The overall adverse perinatal outcome was significantly higher in those with threatened miscarriage group $(49.1 \%)$ as compared with the control group $(9.1 \%)$. This can be attributed to high incidence of maternal complications in the study group. The mean birth weight was significantly lower in the study group $(2.63 \mathrm{~kg})$ as compared with the control group $(2.99 \mathrm{~kg})$. This was comparable to the study done by Ahmed et al. ${ }^{7}$ The incidence of LBW was significantly higher in those with threatened miscarriage $(33.3 \%)$ as compared with the control group $(8 \%)$. The incidence in the study group was also higher in the study by Hosseini and Yaghoubipour ${ }^{13}$ (12.3\%). Majority of women attending our hospital belonged to lower middle class, who are poorly nourished. This could be the possible reason for higher incidence of LBW in our study compared with other studies.

Apgar score at 5 minutes of less than 7 was found in $18.2 \%$ of study group and in no babies of control group, the result being statistically significant. In comparison, in the study by Hosseini and Yaghoubipour, ${ }_{13}^{13} 17.4 \%$ of babies had Apgar score of less than 7 at 5 minutes. The frequency of NICU admission was $35 \%$ in study group vs $3.4 \%$ in the control group. Majority of admissions were due to LBW and low Apgar score which is a logical sequence of preterm birth. Saraswat et $\mathrm{al}^{12}$ and Hosseini and Yaghoubipour ${ }^{13}$ also found NICU admissions to be significantly higher in babies born in those with threatened miscarriage.

\section{CONCLUSION}

The current study reports that women with first-trimester vaginal bleeding are at increased risk of adverse pregnancy outcomes, such as spontaneous miscarriage, PPROM, PROM, IUGR, oligohydramnios, LBW babies, preterm delivery, and increased perinatal morbidity. Thus, in early pregnancy, miscarriage and adverse maternalfetal outcome can be predicted, so as to rationalize strict antenatal surveillance and follow-up during pregnancy.

\section{REFERENCES}

1. Bellieni CV, Buonocore G. Abortion and subsequent mental health: review of the literature. Psychiatry Clin Neurosci 2013 Jul;67(5):301-310.

2. Coleman PK. Abortion and mental health: quantitative synthesis and analysis of research published 1995-2009. Br J Psychiatry 2011 Aug;199(3):180-186.

3. Hasan R, Baird DD, Herring AH, Olshan AF, Jonsson Funk ML, Hartmann KE. Patterns and predictors of vaginal bleeding in the first trimester of pregnancy. Ann Epidemiol 2010 Jul;20(7):524-531.

4. Lykke JA, Dideriksen KL, Lidegaard Ø, Langhoff-Roos J. First-trimester vaginal bleeding and complications later in pregnancy. Obstet Gynecol 2010 May;115(5):935-944.

5. Kumar N, Gupta N, Kishore J. Kuppuswamy's socioeconomic scale: updating income ranges for the year 2012. Indian J Public Health 2012 Jun;56(1):103-104.

6. Dongol A, Mool S, Tiwari P. Outcome of pregnancy complicated by threatened abortion. Kathmandu Univ Med J (KUMJ) 2011 Jan-Mar;9(33):41-44.

7. Ahmed SR, El-Sammani MK, Al-Sheeha MA, Aitallah AS, Khan FJ, Ahmed SR. Pregnancy outcome in women with threatened miscarriage: a year study. Mater Sociomed 2012 Feb;24(1):26-28.

8. Boriboonhirunsarn D, Buranawattanachoke S. Ultrasonographic characteristics in patients clinically diagnosed with threatened abortion. J Med Assoc Thai 2007 Nov;90(11): 2266-2270.

9. Amirkhani Z, Akhlaghdoust M, Abedian M, Salehi GR, Zarbati N, Mogharehabed M, Arefian S, Jafarabadi M. Maternal and perinatal outcomes in pregnant women with first trimester vaginal bleeding. J Family Reprod Health 2013 Jun;7(2):57-61.

10. VelezEdwardsDR, BairdDD,HasanR,SavitzDA,HartmannKE. First-trimester bleeding characteristics associate with increased risk of preterm birth: data from a prospective pregnancy cohort. First-trimester bleeding characteristics associate with increased risk of preterm birth: data from a prospective pregnancy cohort. Hum Reprod 2012 Jan;27(1):54-60.

11. Dadkhah F, Kashanian M, Eliasi G. A comparison between the pregnancy outcome in women both with or without threatened abortion. Early Hum Dev 2010 Mar;86(3):193-196.

12. Saraswat L, Bhattacharya S, Maheshwari A, Bhattacharya S. Maternal and perinatal outcome in women with threatened miscarriage in the first trimester: a systematic review. BJOG 2010 Feb;117(3):245-257.

13. Hosseini MS, Yaghoubipour S. Late pregnancy outcome in women with vaginal bleeding in their first trimester. J Obstet Gynaecol India 2013 Oct;63(5):31. 